\title{
Resistance to distortion as a metric for pattern goodness
}

\author{
R. F. COWAN \& W. D. BLISS \\ UNIVERSITY OF SOUTH FIORIDA
}

The breakdown of binocular fusion (doubling of image) as a function of increasing lateral separation of dichoptically presented images was explored as a metric for an operationaldefinition of "good figure." It was found that those patterns constructed so as to reflect the Gestalt principles of good figure were significantly more resistant to this type of distortion than were patterns whose configurational properties generally reflect "poor figure."

Wertheimer's Law of Prägnanz, as given by Koffka 1935), states ". . psychological organization will always be as 'good' as the prevailing conditions allow. In this definition, the term 'good' is undefined. It embraces such properties as regularity, symmetry, simplicity, and others..." This statement lays the foundation for a psychophysics of form. The fact that the term "good" is left undefined is indicative of Wertheimer's recognition that form has many parameters, and that "goodness" is an appellation to forms that express these parameters in specific relations. Although the Gestalt principles of grouping are couched in quantitative terms, i.e., continuation, closed form, etc., it is evident that the need for quantitative measures, and the complementary character of qualitative and quantitative description were clearly recognized. Thus, Koffka states (Ch. 4, p. 174), "Clearly the quantitative and qualitative character are not two separate characteristics, but only two aspects of one and the same principle."; and, "As real organizations, units and shapes must have a formula which will express them quantitatively...". These statements, and the principles they embody, have generated considerable experimentation directed toward isolating the parameters of form, determining a metric by which to measure their interaction, and specifying, operationally, goodness as a function of this interaction.

An enduring functional property ascribed to "good figures" is that they are stable (Kohler, 1947), hence, resistant to distortion. If an objective measure of the resistance of forms to distortion can be determined, then this metric will provide a legitimate, operational definition of the general concept of "good form." Further, if this metric can be shown to discriminate differentially between the resistance of various forms to distortion, then a method exists whose metric can be standardized such that any form can be classified on the basis to which it approaches goodness. Parameters of particular forms may then be varied and a quantitative description given of the relative degree to which each contributes to the total "pattern goodness."

The metric we propose in this exploratory study is that which measures the resistance to distortion, or point of fusional breakdown, of dichoptically presented forms as a function of ocular divergence induced by lateral separation of stimulus targets. The hypothesis is that good forms are resistant to distortion, and will be more resistant to distortion of the type here explored than "poor forms."

\section{Method}

Apparatus. A standard Keystone Opthalmic Telebinocular stereoscope was used, with target holder set at a convergence distance of 30 in., which for this instrument is a prismatic lens conversion of 1.25 diopters. The target holder permits presentation of individual stimulus targets in each monocular field, which are seen by the viewer as a single, fused target in a $3 \mathrm{x}$ 2 in. binocular field. Fusion strength, or resistance to distortion, may then be tested by separating the individual targets laterally from the vertical meridian, forcing the eyes to greater divergence until the fused image breaks down (doubles) in whole or in part. All targets were viewed under normal room illumination.

Stimulus materials. Six stimulus figures were constructed, three of which conformed to the major Gestalt criteria of goodness and three of which did not. The patterns thus constructed are shown in Fig. 1. Patterns $A, B$, and $C$ were rendered as good patterns and constituted Group 1. Patterns D, E, and F, rendered as poor patterns, comprised Group 2. These six patterns were then drawn in duplicate (one for the left monocular field, and one for the right) with black ink on white poster boards $3.5 \mathrm{in}$. wide and $9.5 \mathrm{in}$.long. Each pattern was centered vertically in a $2 \times 2$ in, area $1 / 2$ in. from the right, or left (depending on monocular field) edge of the card.
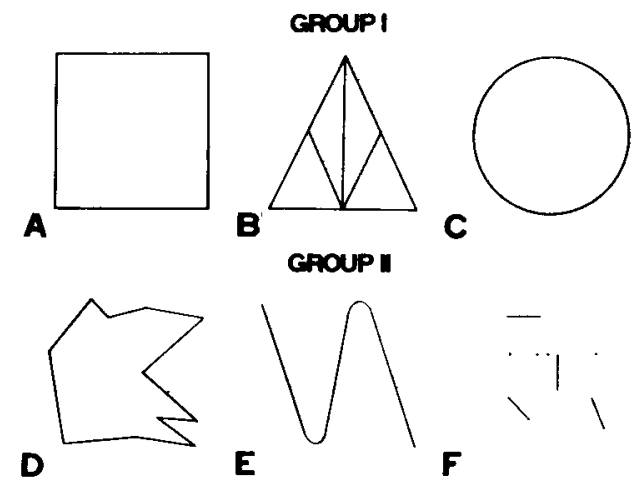

Fig. 1. 
Subjects. Twenty randomly selected male and female students from an introductory course in psychology served as Ss. All Ss either had 20/20 vision, or wore corrective lenses. No attempt was made to control for the differential effects of lateral and vertical phoria between Ss. Since such effects would be evenly distributed across the entire target series, those Ss in whom the effects of phoria operated most strongly would simply experience target distortion for all targets at a lesser degree of lateral separation than would Ss in whom phoria was less operative. Resistance to distortion of the individual target, however, would remain a function of its indigenous characteristics.

Procedure. Ss entered the experimental room one at a time and were seated at a table upon which the test apparatus was situated. $\mathrm{S}$ was then instructed to look into the apparatus (which presented a plain white field) and arrange himself comfortably. $S$ was then told that he would be shown a paired series of geometric forms which he would see as a single fused image. The first pair of targets were then inserted into the apparatus, and $S$ directed to observe and report what he saw. In each instance $S$ reported seeing a single stimulus target. $\mathrm{S}$ was then told that the pattern might tend to break up, and then re-fuse; however, he was to report only when the pattern, in whole or in part, could no longer be seen as s single, fused image. E then separated the stimulus targets from the vertical meridian at an even rate by hand until $S$ reported doubling of the images. Note was made of the degree of lateral separation between the two targets in .01 in. $S$ was then instructed to look away from the eyepiece, and a new pair of targets was inserted. The procedure was then repeated for all six target pairs. In each instance, once the targets were inserted in the apparatus and $S$ had returned to viewing, he was given ample time to adjust to the new stimulus target. No instructions were given $S$ with regard to any specific fixation point in the visual field. Target presentation was counterbalanced across all Ss to control for fatigue, practice, and response bias effects. Further, each sequence was so arranged as to appear an equal number of times across the $20 \mathrm{Ss}$. Results

The mean resistance to distortion (as measured by the degree of lateral separation between targets of each monocular field at the point of fusion breakdown) for each target pattern, as well as the means for each

Table 1. Lateral separation of stimulus figures at breakdown of fusion (in hundredths of in.).

$$
\text { Group } 1
$$

Group 2

\begin{aligned} & \hline Pattern $A=.96$ Pattern $D=.59 \\ &$\hline Pattern $\mathrm{B}=.83$ Pattern $\mathrm{E}=.76 \\ &$\hline Pattern $\mathrm{C}=.98$ Pattern $\mathrm{F}=.69 \\ &$\hline Mean $=.92$ Mean $=.68 \\ &$\hline\end{aligned}

Table 2.

\begin{tabular}{ccccc}
$\begin{array}{c}p<.01 \\
a b\end{array}$ & $\begin{array}{c}p>05 \\
a c\end{array}$ & $\begin{array}{c}p<.01 \\
\text { ad }\end{array}$ & $\begin{array}{c}p<.01 \\
\text { ae }\end{array}$ & $\begin{array}{c}p<.01 \\
\text { af }\end{array}$ \\
\hline $\begin{array}{c}p<.01 \\
b c\end{array}$ & $\begin{array}{c}p<.01 \\
b d\end{array}$ & $\begin{array}{c}p<.05 \\
b e\end{array}$ & $\begin{array}{c}p<.01 \\
b f\end{array}$ \\
$\begin{array}{c}p<.01 \\
c d\end{array}$ & $\begin{array}{c}p<.01 \\
c e\end{array}$ & $\begin{array}{c}p<.01 \\
\text { cf }\end{array}$ & \\
$\begin{array}{c}p<.01 \\
\text { de }\end{array}$ & $\begin{array}{c}p<.05 \\
\text { df }\end{array}$ & & \\
$\begin{array}{c}p>05 \\
\text { ef }\end{array}$ & & & \\
\hline
\end{tabular}

group (1 and 2), are presented in Table 1. Group means were determined by pooling $\mathrm{Ss}^{\prime}$ responses to each pattern in that group and using the mean of these responses as Ss' score for that group. The mean of these scores was then computed for the group means. Individual pattern means were taken on all S's responses to each pattern. A simple analysis of variance between individual patterns was significant at the .001 level $(F=7.35)$. A matched $t$ between the means of Group 1 and Group 2 was also significant at the .001 level $(t=7.69)$. Table 2 presents significance levels for matched ts computed between all possible combinations of single patterns. Differential resistance to distortion between Patterns $A$ and $C$, and $E$ and $F$ were not significant. Patterns $D$ and $F$, and $B$ and $E$ differed significantly at the .05 level. All other pattern differences were significant at the .01 level.

\section{Discussion}

The data clearly support the hypothesis that lateral separation of dichoptically presented forms is a mode of distortion to which "good forms" are resistant. Further, this method provides a metric which discriminates differentially between forms. This discrimination is powerful between groups of good forms and poor forms, as well as between single patterns from each group. It becomes weaker between patterns of the same group; however, differential resistance is still in the direction of good form. Thus, it is anticipated that future work will be conducted with an instrument which provides precise quantification of both lateral separation and ocular divergence. It will then be possible to produce a normative standard metric across forms. What is of principle import here, however, is that the general concept of "figural goodness" has been given an operational definition which can be utilized across a wide variety of variable parameters.

References

KOFFKA, K. Principles of Gestalt psychology. New York: Harcourt, Brace, 1935

KOHLER, W. Gestalt Psychology. New York: Liveright Publishing Corp., 1947.

Note

1. This research was supported by NIMH Grant No. MH 12749-01 and the University of South Florida Research Council. 